\title{
After Izimbizo, what next? A participatory development communication approach to analysing feedback by the Limpopo Provincial Government to its citizens
}

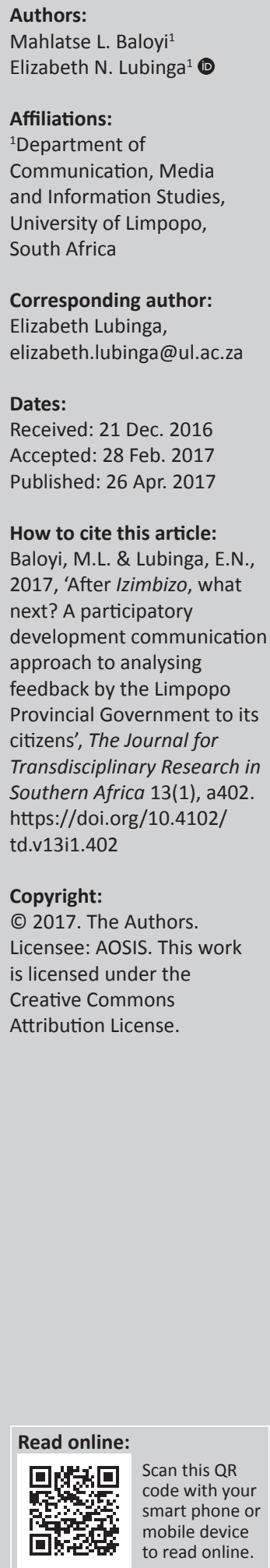

\begin{abstract}
The new democracy in South Africa advocates for a community participatory approach in matters of governance using the Imbizo (plural, Izimbizo) among other channels. Existent studies on Imbizo indicate that the major motivation for organisation of such gatherings by governments appears to be interactive community mobilisation, rather than feedback to matters raised during such gatherings. However, if participatory development aided by communication is to be effective, then it is imperative that feedback is provided not only during a once-off interaction with citizens by government but also, and more importantly, as follow-up to grievances raised during Imbizo. Adoption of Imbizo as effective channels of communication necessitates a provision of quality feedback by government to service delivery concerns raised at the Imbizo.

A qualitative study was conducted using semi-structured interviews with participants from three local municipalities in Limpopo Province. Findings reveal that the Limpopo Provincial Government does not provide adequate feedback to service delivery matters raised by communities during Imbizo. The study is relevant to the scholarship of government communication in the context of public discourse, which attributes growing sporadic service delivery protests to poor or inadequate feedback from government.
\end{abstract}

\section{Introduction}

The advent of the South African democracy in 1994 compelled government to partner with all its citizens in order to address governance issues affecting their daily lives. This democracy followed 45 years of struggle during which the then government is alleged to have operated under a culture of secrecy and disinformation to its citizens (Comtask Report 1996:13). Under the new democracy, it appears that government has gravitated towards partnering with citizens in order to deal with issues affecting their daily lives. Rasila and Mudau (2013:13) posit that this partnership between government and communities can work to identify viable and desirable development initiatives through development communication. Such partnerships between government and citizens, which aim to achieve developmental goals for communities, form the core of development communication. A participatory development communication approach, therefore, provides an ideal platform for studying community participation and feedback relating to partnerships with government.

In light of the participatory approach, the South African Government adopted the Imbizo and Thusong Service Centres as the main tools of development communication to bridge the information gap and address service delivery backlogs in rural areas (Government Communicators' Handbook 2014:65). The Imbizo is crucial to this study because it has become the most popular platform for engagement due to its direct, face-to-face interaction between citizens and government representatives. Imbizo is a traditional Zulu word, which means a 'calling', where traditional leaders summon people to solve societal issues of common interest (Mabelebele 2006:104). Chaka (2014:358) notes that the practice of Imbizo is traditionally used to resolve community challenges by robustly and thoroughly engaging with traditional leaders. However, today, the term Imbizo has become more commonly associated with government gatherings that afford people the opportunity to participate in solving issues that directly affect their lives (Hartslief 2008:1). The Imbizo is regarded by government as a 'style of interactive governance and communication [that] should promote dialogue between government and people without mediation' (Government Communicators' Handbook 2014:57). 


\section{Izimbizo as platforms for citizen participation}

Although the Imbizo was introduced as an approach to resolve community issues, some critics point out a number of inadequacies (Kondlo 2010; Rasila \& Mudau 2014). For example, Kondlo (2010:388) argues that the Imbizo appears to be a travesty of the good it should be, because it lacks authentic participation practices by not bringing any solutions to the problems that people are facing. In practice, although Izimbizo are public communication platforms, as Kondlo argues, they often fail to facilitate participation because people are mobilised to meet and listen to government officials, rather than to participate. Rasila and Mudau (2014:615) too note that the government Imbizo does not engage communities, but is simply a process of mobilisation.

Participation through Imbizo would be an ideal way of involving affected community members with their own matters (Rasila \& Mudau 2013:14). These authors conceptualise participation as relating to active community engagement in matters of development to ensure that communities identify their own development problems. Inherent in this perspective is that the community is expected to be an active participant in monitoring and evaluating development processes. However, it may be argued that the Imbizo may not be the best forum to ensure effective participation, simply because it lacks feedback. As Kondlo (2010:390) observes, the Imbizo lacks a proper feedback mechanism and does not provide authentic community participation.

In practice, the current state of affairs of Imbizo in the Limpopo Province appears to be that feedback on issues of service delivery previously raised during gatherings is inadequate. There seems to be no operational feedback mechanism to grievances raised during Imbizo by citizens. The Imbizo process is rendered incomplete and ineffective if there is no follow-up to issues raised during previous meetings, because the purpose of this gathering is to provide a platform for airing grievances. Therefore, it is not only logical but also incumbent upon the Limpopo Provincial Government to respond to development matters arising during Izimbizo. The government ought to ensure that further feedback is provided as a follow-up to such gatherings in order to provide a cyclical communication process, an embodiment of effective communication. It is within this context that this article analyses the quality of feedback following some Izimbizo that were conducted by the Limpopo Provincial Government.

A number of key questions arise: What kind of feedback is given to communities in response to concerns raised during Izimbizo? To what extent does the Limpopo Provincial Government provide feedback to issues previously raised during Izimbizo? What factors limit the provision of feedback from the Limpopo Provincial Government to its citizens following the Imbizo? It would be ideal within the ambit of the participatory development communication approach for regular interaction through available channels of communication to continue after the Imbizo in order to inform citizens about the decisions taken by government. Although some limited research has been conducted on Imbizo in South Africa, most of the available studies do not address feedback to matters by citizens raised at these meetings (Hartslief 2008; Kondlo 2010; Mathagu 2010; Netshitomboni 2007). This article, thus, attempts to contribute to the existing body of government communication scholarship and inform praxis by examining feedback to issues raised during governmentcitizen Izimbizo.

\section{Theorising community participation and feedback}

In positioning the twin concepts, community participation and feedback, within participatory development communication, it should be noted that the two are applied differently in developed and developing countries. There is no uniform approach and application of community participation, as it varies according to the ethos, principles and available tools of each country (Msibi \& Penzhorn 2010:226). In addition, Bessette (2004:116) argues that participatory development communication has different tools for facilitating participation such as interpersonal communication, mass media, traditional media and information communication technology. Grounding the community participation concept within the context of development communication necessitates that this study also examines the tools used to support the participation of people in governance.

Considering the differences in the application of participation and feedback, there is general consensus about the discourse of digital or online participation as adopted by developed (Western) countries. Bonson, Royo and Ratkai (2015:52) found that proficient citizen-participation countries such as Spain and Germany prefer to use technology to facilitate citizen participation because it is assumed that citizens of such countries are technologically savvy. Their study revealed that citizens become involved in government affairs by means of the Internet and that as many as $70 \%$ of the participants prefer digital communication channels.

In addition to the use of digital participation, a study conducted in Germany argues that online participation epitomises changes in the current communication environment, as most citizens resort to online platforms to share information and interact with government officials (Heinze, Schneider \& Ferie 2013:370). However, these studies (Bonson et al. 2015; Heinze et al. 2013) do not address how feedback is conducted through social media sites to ensure a complete process of participation. The paucity of feedback in existing studies about community participation propels the need for this study to delve into the subject of the feedback phenomenon in online communication.

Another study, conducted by Colineau, Paris and Vander Linden (2012), addresses the commonality of the adoption of digital participation. The researchers of this study found that in Australia, government has migrated from traditional 
to new online means of participation (Colineau et al. 2012: 177-178). Their study revealed that the adoption of online participation by government adds to the notion of keeping citizens informed. The main communication tools that were found to be effective were Facebook and Twitter. As Sanders and Canel (2013:310) point out, digital participation has also predominantly been used for citizen engagement in Singapore, where government heavily relies on websites and social media networks to frequently consult with citizens about policies. However, although these studies relate the efficiency of communication using digital platforms, they do not expound on the nature of the feedback processes between government and citizens regarding the issues raised on such online platforms.

\section{The Imbizo paradox}

Central to the practice of community participation and feedback, developing countries such as South Africa have adopted traditional tools such as the Imbizo for participation as opposed to online participation (Booysen 2009:13). It should be noted that the Imbizo is not the only tool used for participation. Nevertheless, this article focuses on the Imbizo because of its participatory nature. Participation between communities and government is the crucial trigger inherent in the Imbizo, because people are afforded the opportunity to decide on what kind of services they want government to render, because they are the end-users (South African Public Service Commission 2008:2).

The paradox lies in the fact that contrary to the purpose of Izimbizo as tools of participation, actual community participation in these platforms is inhibited because government makes decisions on when and how people should participate. As such community input is often not implemented. The unintended effect of the Imbizo programme is that communities feel marginalised and disempowered by the very instrument that was meant to empower them through participation, to the extent that they perceive government services as not belonging to them (Kondlo 2010; Mathagu 2010; Netshitomboni 2007; Silima \& Auriacombe 2013). These researchers argue that Izimbizo lack authenticity as tools of participation. For example, Kondlo (2010:386) argues that the Imbizo is not an appropriate platform for communities to air their grievances due to limited participation. Another defect in the Imbizo platform appears to be partial participation, the fact that not everyone is allowed to participate (Mathagu 2010:116). Netshitomboni (2007:181) found that the Imbizo lacks interactivity because it does not pave way for extensive discussion by citizens, and community suggestions are not implemented. The mere act by government of not implementing community contributions may suggest to citizens that their participation is not instrumental to community development.

\section{Paucity of feedback}

Currently, most notably in relation to literature about the Imbizo, there is no empirical evidence suggesting that the platform directly offers solutions to problems affecting communities. As such, some researchers have questioned, albeit in disconcert, the relevance of the Imbizo in contributing to addressing service delivery backlog (Kondlo 2010; Mabelebele 2006; Mukhudwana 2015; Netshitomboni 2007). For instance, Kondlo (2010) suggests that Izimbizo lack a proper feedback system on previously raised issues relating to the provision of services. This may indicate that the Imbizo cannot meaningfully contribute to the reduction of service delivery backlog, if it does not provide follow-up to previously raised, but unresolved, issues of service delivery. In the case of the Limpopo Provincial Government, Ngobeni (2015) reveals that during that year, the Premier of the Province launched an Extended Public Works Programme during Izimbizo whereas they were held to provide feedback. This may possibly raise challenges in terms of citizen expectations about the role of the Imbizo especially with regard to feedback provision. As the World Bank (2007:6) argues, there is still poor implementation of service delivery redress mechanisms and provision of insufficient feedback. Rowe and Frewer (2005) suggest that 'Imbizo feedback' is non-existent in practice, as there is no empirical evidence of redress, follow-up or responsiveness to matters raised.

Considering the inadequacy of feedback or responsiveness, there has recently been a growing amount of public discourse, suggesting a relationship between service delivery protests and lack of responsiveness from government (Kamwendo 2016; Kotane 2016). Kamwendo (2016) concludes that government only appears to respond or provide feedback to communities whenever there is 'smoke', in apparent reference to burning of vehicle tyres or buildings during such protests. Kotane (2016) too argues that there does not seem to be any reason for government to address communities' needs unless violent protests erupt. This suggests that the more violence during community protests, the faster the response by government. It is against this background that Tadesse et al. (2006:22) assert that service delivery protests become acceptable and are utilised by communities as channels of communication whenever government is unresponsive to matters. However, this article, specifically due to the methodology adopted by the study, cannot claim to establish a causal link between lack of feedback and service delivery protests.

\section{The participatory paradigm}

It is historically noted that development communication evolved from modernisation to dependency, and later to a participatory paradigm. For purposes of this article, the focus is on the latter paradigm, which emphasises feedback, participation and empowerment.

The Imbizo as a participatory tool in South Africa is used to strengthen community participation, exert control and possibly provide feedback on matters raised (Government Communicators' Handbook 2014:55). This implies that two principal benefits may be derived from the existence of Imbizo: the channelling of service delivery and a sense of 
ownership by communities on account of the right to receive feedback on the issues they raise.

In light of those benefits, Tomaselli and Chasi (2011:212) state that, firstly, the participatory paradigm enables beneficiaries to sustain development because through their participation, they develop skills and abilities to the degree that their growth and transformation lead to self-affirmation. Secondly, the paradigm enables ordinary people to take control of their own development, where development can continue without the assistance of the benefactors. In addition to these benefits, Servaes (2008:169) contends that the participatory paradigm decentralises power where beneficiaries can assume the duties of ownership.

This theory accentuates the need not only for beneficiaries of development to actively participate in related activities but also for them to engage in interactive feedback with benefactors (Bessette 2006:54). The theory is, thus, central to the article in three ways. Firstly, it helps to point out the need for community participation in development programmes through platforms such as the Imbizo. Secondly, it stresses the important role of regular feedback in participatory development projects and initiatives. Finally, it places emphasis on the need for public meetings such as Izimbizo to adopt a two-way participatory approach that benefits both citizens and government. As a result, both parties attain equal opportunities at Izimbizo enabling them to share knowledge as opposed to linear communication (from government to citizens) aimed at persuasion (Otto \& Fourie 2016:28).

\section{Methodology}

This article adopted a case study within the qualitative approach. A qualitative research approach was invaluable to study Izimbizo because it could provide description about the feedback phenomenon. Two forms of non-probability sampling techniques, purposive and convenience, were used to select 27 participants who are well versed with Imbizo operations from three different local municipalities in Limpopo: Molemole, Makhado and Greater Giyani Municipality. According to the Limpopo Provincial Government (2014:15), Limpopo Province consists of 25 local municipalities and 12 hold Izimbizo every financial year. Thus, the selected local municipalities are three of the 12 municipalities that have hosted Izimbizo in the 2014/2015 financial year. The study was conducted in 2016, and therefore in order to conduct a post-analysis of Izimbizo, it could best lend itself to the 2014/2015 financial year. According to the Limpopo Provincial Government Research Office, six Izimbizo were conducted between May and November 2016. The 2017 gatherings are scheduled to commence in April 2017, which makes the 2016/2017 financial year incomplete for purposes of this study, considering that it assessed feedback to already conducted Izimbizo (Bvuma 2017). Participants were divided into three categories according to their designation: three community members who regularly attend Izimbizo, three community development workers and three ward committee members from each of the three above mentioned municipalities.

Data were collected from participants who were interviewed using semi-structured interviews, as well as content from some Limpopo Provincial Government documents relating to Izimbizo. Documents that were analysed included the State of the Province Address (SoPA), Imbizo progress reports and the Limpopo Provincial Government Communication Strategy. A database was obtained from the Limpopo Office of the Premier and was used to contact the participants telephonically in order to schedule interviews. Consent was sought from the participants. Interviews were individually conducted with participants in their natural settings, the municipalities Molemole (south) to Makhado (north) and Giyani (north-west of Limpopo Province). Permission was sought from the participants to record the interviews. While recording the interviews, it was also important to note what was being observed such as personal reaction of the participants, to enhance the verbal communication.

The audio-recorded interviews were transcribed verbatim and later typed using Microsoft Word. Data were categorised by using open and axial coding (Du PlooyCilliers, Davis \& Bezuidenhout 2014:233). By applying open coding, data were broken down into chunks of the text before attaching meaning through information coding. Axial coding was used to categorise the data into the emerging themes.

In terms of document analysis, the study applied a deductive approach using thematic analysis to categorise the data into the pre-existing themes that emerged from semi-structured interviews. Bowen (2009:32) points out that when applying the thematic method, it is important for researchers to have themes prior to the analysing process, particularly if the documents are supplementary to other research methods used in the study. The process of document analysis involved discovering, selecting, judging and synthesising data contained in documents.

\section{Findings and discussions}

A number of themes emerged from the data that were collected from the participants.

\section{Poor quality and quantity of feedback}

The findings of this study reveal that there is minimal and uneven distribution of feedback in the three municipalities, in relation to concerns raised during Izimbizo, specifically about service delivery. Two out of the three municipalities mentioned that they do not receive feedback from government. For example, participants, particularly in Greater Giyani and Makhado Municipalities, revealed that:

'Feedback is not given at all, given to the people at all. I have not even heard government telling us about what they promise.

Every time people expect good services from us as the ward committees, but the problem is that we have wait for top officials 
to brief us before we can go to the people [sic].' (Ward Committee Member 2, Makhado Municipality)

The response above, among others, suggests that the Imbizo does not attempt to redress or provide feedback to the affected communities. It further suggests that Izimbizo are not effectively utilised by the Limpopo Provincial Government to serve the purpose of providing feedback.

\section{Praxis versus verbal feedback}

Participants reported that the practical provision of services is more important to them than verbal feedback. It is evident from most of the responses that feedback without tangible deliverables is not considered to be enough. As illustrated below, some communities consider actualisation of their concerns as feedback:

'There is feedback in terms of communicating in our municipality, but all we want is the services. Even if government can give us feedback on the matters brought to their attention and do not fulfil what they promised us, yet we are still without what we needed [sic].' (Ward Committee Member 1, Molemole Municipality)

With reference to the above comment, it is considered that verbal responses from government following concerns raised at Izimbizo make no difference to them if services are not delivered to the communities. Community expectations seem to be such that verbal feedback cannot replace service delivery, despite regular interaction between communities and government. In other words, communities appear to prefer actual rendering of services to regular verbal feedback on raised grievances. These responses suggest that verbal feedback does not alleviate the developmental burden and challenges that communities are faced with, yet actual delivery of services does.

\section{Barriers to feedback provision}

Two factors seemed contribute to the limitation of feedback on issues raised by communities: dysfunctional ward committee structures and poor accountability. It must be emphasised that due to the qualitative methodology of the study, a causal link cannot be established between the two identified variables, although such a relationship was suggested by participants.

\section{Dysfunctional ward committee structures}

The findings show that ward committee structures are dysfunctional in terms of providing feedback to communities. The majority of the participants mentioned that they do not receive feedback about their grievances because ward committee members are incompetent in terms of communicating with their communities. Regarding the irregularity of feedback, for example, a participant said:

'Ward committees provide feedback whenever they want and it is difficult for us as community members to keep abreast of government's fulfillments and that is unacceptable [sic].' (Community Member 1, Greater Giyani Municipality)

\section{Poor accountability}

Poor accountability about service delivery by the Limpopo Provincial Government was found to be another factor hindering the Imbizo feedback. One of the participants argued as follows:

'There is no accountability in our government. Everything is done without the knowledge of people. Government is afraid to tell people about the progress of development because it knows that people will be angry at them. Sometimes it is because government did not spend wisely the allocated money and is ashamed to keep us posted about the progress made. That's why in most instances, government give excuses of insufficient budget whereas cost-benefit analysis was done prior to the commencement of projects [sic].' (Community Development Worker 3 in Greater Giyani Municipality)

The findings suggest that the Limpopo Provincial Government is unwilling to account to the public, because of its inability to manage finances. The participant suggests that government officials rely on the 'budget-constraint' claim as the commonly given excuse, to avoid providing feedback to the citizens.

\section{Communication channels}

Three communication channels that are deemed appropriate for providing feedback on the matters raised during Izimbizo were suggested by the participants. Some participants in Molemole Municipality indicated that the Imbizo is an ideal platform on the basis of its direct interaction between government and the public. For example, a ward committee member and a community development worker said:

'Imbizo is the appropriate channel to give feedback because it gives government an assurance that people have heard the message and government can see how many have attended [sic].' (Ward Committee Member 3, Molemole Municipality)

'At an Imbizo, feedback can be sent to a multitude at the same time [sic].' (Community Development Worker 1, Molemole Municipality)

The majority of the participants especially in Molemole Municipality preferred traditional channels such as radio as opposed to digital ones:

'The most preferred channel was radio, which is deemed to be informative and less expensive in terms of cost and accessibility. Although there has no feedback through the Imbizo forum, radio is used to give us clarity on the service delivery matters [sic].' (Community Development Worker2, Greater Giyani Municipality)

The participants revealed that social media platforms such as Facebook and Twitter are the main digital communication channels that have gained momentum in this era, and which could be used. The majority of the participants indicated that they prefer feedback on issues raised at Izimbizo to be provided through Facebook. The following views were expressed:

'I prefer Facebook because the communication environment has drastically changed over the past years. None in this year have 
time to sit next to their radios to listen to dictated conversation between politicians and radio presenters. Feedback may also be given via Facebook as we walk everywhere with our cellphone and other gadget in our bags [sic].' (Community Member 3, Greater Giyani Municipality)

'I have access social media for communication and research [sic].' (Community Development Worker 2, Makhado Municipality)

The overarching idea from the results is that online media have the potential to grow into feedback channels in the Limpopo Province. However, challenges such as access to rural communities may arise and should be given due consideration in decision-making. Nevertheless, Facebook allows individuals to personalise their communication. This implies that communication may be confined to an individual and government. The results further show that the social media are increasingly becoming a dominant form of communication today.

\section{Recommendations}

The following recommendations are suggested from the study.

The Limpopo Provincial Government should consider utilising a parallel strategy in addition to the main communication strategy: Izimbizo. The Izimbizo strategy could be used to outline the focus or objectives of government to the citizens in addition to other supporting channels of communication such as radio and social media.

For instance, it would be ideal for the Limpopo Provincial Government to purchase time slots on both the South African Broadcasting Corporation (SABC) and commercial radios such as Capricorn FM to attend to matters raised by citizens. This could be done every quarter in the year to inform the affected communities on either progress made or challenges impeding the completion of services, to allow for frequent communication.

Arising from the study, there is need for affected communities to have access to progress reports containing all issues raised at Izimbizo. These reports could be uploaded on government departments' websites, which could ultimately minimise public distrust.

\section{Conclusions}

The article has argued that communities expect feedback on the matters raised at Izimbizo to be provided in a tangible form such as actual delivery of services rather than verbal feedback. At present, there is minimal and uneven distribution of feedback in the Limpopo Province. Dysfunctional ward committee structures and poor accountability appear to be major contributory factors to uneven provision of feedback, whereas poor accountability hinders the Limpopo Provincial Government from providing adequate feedback. Room for accountability about development issues exists in the form of Imbizo progress reports, although these reports are held confidential and strictly meant for the Premier, Members of Executive Council (MECs) and the Director General at the Premier's Office in the Limpopo Province. With regard to channels for feedback, radio is the most preferred specifically for service delivery matters, with online media specifically Facebook viewed to have potential for growth in future. At present, apart from radio, the Imbizo is deemed to be a possible communication channel due to its cost-effectiveness and accessibility with potential for further interactivity if feedback is provided by government to previous grievances.

Further research through quantitative studies could be conducted to establish possible causal links between postIzimbizo feedback between government and citizens.

\section{Acknowledgements}

The authors would like to thank Mr David Bvuma for providing information about the 2016/2017 Imbizo schedule.

\section{Competing interests}

The authors declare that they have no financial or personal relationships which may have inappropriately influenced them in writing this article.

\section{Authors' contributions}

M.L.B. was responsible for conceptualisation of the project, collected, analysed and interpreted the data. E.L. made conceptual contributions and supervised the project.

\section{References}

Bessette, G., 2004, Involving the community: A guide to participatory development communication, Southbound, Ontario, CA.

Bessette, G., 2006, People land and water: Participatory development communication for natural resource management, International Development Research Centre, Ottawa, Canada.

Bonson, E., Royo, S. \& Ratkai, M., 2015, 'Citizens' engagement on local government's Facebook sites. An empirical analysis: The impact of different media and content types in Western Europe', Government Information Quarterly 32, 52-62. https:// doi.org/10.1016/j.giq.2014.11.001

Booysen, S., 2009, 'Public participation in democratic South Africa: From a popular mobilisation to structured cooperation and protests', Journals of Politeia 28(1), $1-27$.

Bowen, G.A., 2009, 'Document analysis as qualitative research method', Qualitative Research Journals 9(2), 27-40.

Bvuma, D., 2017, Imbizo schedule, email, 20 February 2017, BvumaD@premier limpopo.gov.za

Chaka, M., 2014, 'Public relations (PR) in nation-building: An exploration of the South African presidential discourse', Public Relations Review 40, 351-362. https://doi. org/10.1016/j.pubrev.2013.11.013

Colineau, N., Paris, C. \& Vander Linden, K., 2012, 'Government to citizen communications: From generic to tailored document in public administration', Information Polity 17, 177-193.

Comtask Report, 1996, A vision for government communication in South Africa, Government Printers, Pretoria.

Du Plooy-Cilliers, F., Davis, C. \& Bezuidenhout, R., 2014, Research matters, 2nd edn., Juta, Cape Town.

Government communicators' handbook, 2014, Government Communication and Information System (GCIS), Government Printers, Pretoria.

Hartslief, O., 2008, 'The presidential public participation programme (Imbizo) as participatory policy-making', MA dissertation, University of Johannesburg, Johannesburg.

Heinze, J., Schneider, H. \& Ferie, F., 2013, 'Mapping the consumption of government communication: A qualitative study in German', Journal of Public Affairs 13 370-383. https://doi.org/10.1002/pa.1483 
Kamwendo, S., 2016, Why do authorities only listen when there is fire medium? AM Live Interview on SAFM, 19 May, Johannesburg.

Kondlo, K., 2010, 'Making participatory governance work: Re-inventing Imbizo forums in South Africa', Centre for Africa Studies 45, 385-395.

Kotane, T., 2016, 'Limpopo service delivery protests', interview on Capricorn FM, 10 May, Polokwane.

Limpopo Provincial Government, 2014, 20 years of democracy in Limpopo, Government Printers, Polokwane.

Mabelebele, J., 2006, 'Ideological objectives underpinning Imbizo as a model of communication and governance', Journal of Communicare 25, 103-125.

Mathagu, S.F., 2010, An analysis and appraisal of the Imbizo as an instrument of Democracy in South Africa, MA dissertation, University of South Africa.

Msibi, F. \& Penzhorn, C., 2010, 'Participatory communication for local government in South Africa: A Study of Kungwini Local Municipality', Information Development 26(3), 225-236. https://doi.org/10.1177/0266666910376216

Mukhudwana, R.F., 2015, 'Investigating communication management by government in the Kwa-Zulu Natal Province in South Africa', PhD thesis, University of Pretoria.

Netshitomboni, L.R., 2007, 'Managing participatory development communication The case study for Government Communication and Information System', PhD thesis, University of Pretoria.

Ngobeni, H., 2015, Premier Mathabatha and cabinet met the community of Xitlakati, Limpopo Department of Education, Polokwane.

Otto, H. \& Fourie, L.M., 2016, 'Theorising participation as a communicative action for development and social change', Journal of Communicare 35, 21-39.
Rasila, B.N. \& Mudau, J., 2013, 'Citizen participation in local government: The importance of effective communication in rural development', International Journal of Community Development 1, 12-18. https://doi.org/10.11634/233 028791301321

Rasila, B.N. \& Mudau, J., 2014, 'An effective communication framework for rural development', Prime Journal for Social Sciences 3(3), 612-617.

Rowe, G. and Frewer, L.J., 2005, 'A typology of public engagement mechanisms', Science, Technology and Human Values 30(2), 251-290. https://doi.org/10.1177/ 0162243904271724

Sanders, K. \& Canel, M.J., 2013, Government communication: Cases and challenges, Bloomsbury, London.

Servaes, J., 2008, Communication for development and social change, Sage, New Delhi.

Silima, T. \& Auriacombe, C.J., 2013, 'The role of ward committees in citizen participation and the socio-economic development of communities', Administratio Publica 21(3),42-64.

South African Public Service Commission, 2008, Report on the assessment of public participation practices in the public service, Government Printers, Pretoria.

Tadesse, E., Ameck, G., Christensen, C., Masiko, P., Matlhakola, M., Shilaho, W. et al. 2006, The people shall govern: A research report on public participation in policy processes, Centre for the Study of Violence and Reconciliation (CSVR) and Action for Conflict Transformation (ACTION), Johannesburg.

Tomaselli, K.G. \& Chasi, C., 2011, Development and public health communication, Pearson, Cape Town

World Bank, 2007, World congress on communication for development: Lessons, challenges and the way forward, The International Bank for Reconstruction and Development, Washington, DC. 